\title{
PERANAN AUDIT INTERNAL DALAM MENINGKATKAN EFEKTIVITAS KEGIATAN PEMBIAYAAN PADA BPRS HAJI MISKIN PANDAI SIKEK
}

\author{
1Elfadhli, ${ }^{2}$ Nofri Riski Mulya, ${ }^{3}$ Fatimah Setia Wardhani \\ Institut Agama Islam Negeri Batusangkar \\ e-mail: elfadhli@iainbatusangkar.ac.id \\ Copyright (C) 2021
}

\begin{abstract}
This study was done because An internal auditing was assumpted as one way to assist the bank in safeguarding bank assets, ensure the availability of reliable financial and managerial reporting, and increase bank compliance with applicable laws and regulations. The purpose of this study was to determine the role of Internal Audit in increasing the effectiveness of financing activities at PT. BPRS Haji Miskin Pandai Sikek. The research design was mixed-method. The data was collected through observation, interview, questionnaire, and documentation. The data analysis was done through validity test, reliability test, classic assumption test by means of normality test, simple linear regression test, partial significant test ( $t$ test), and determinant coefficient test (R2). The result showed that the role of internal audit in increasing the effectiveness of financing activities at PT. BPRS Haji Miskin Pandai Sikek had functioned well and was in accordance with the applicable Standards for the Implementation of the Bank's Internal Audit Function (SPFAIB) from 4.7\% to 3.7\% in 2017.
\end{abstract}

Keywords: Audit Internal, Efektifitas, pembiayaan.

\section{PENDAHULUAN}

Perbankan merupakan salah satu lembaga keuangan yang memiliki nilai strategis dalam kehidupan perekonomian. Dalam UU RI No.10 tahun 1998 pengertian Bank itu sendiri adalah badan usaha yang menghimpun dana dari masyarakat dalam bentuk simpanan dan menyalurkan dana ke masyarakat dalam bentuk pembiayaan atau bentuk-bentuk lainnya dalam rangka meningkatkan taraf hidup rakyat banyak. Dengan demikian perbankan akan bergerak dalam kegiatan perekonomian dan berbagai pelayanan jasa.

Agar tercapainya suatu keberhasilan dalam suatu lembaga keuangan, seorang pimpinan harus melakukan suatu langkah manajemen agar tujuan lembaga keuangan tercapai dan terciptanya kesehatan bank. Salah satu langkah yang dapat dilakukan seorang 
manajer adalah melakukan pengawasan terhadap segala sesuatu pekerjaan yang dilakukan seseorang karyawan atau disebut juga dengan pengawasan operasional. Pengawasan menjadi unsur yang sangat penting dalam suatu lembaga keuangan. Karena pengawasan diperlukan untuk memastikan apakah yang direncanakan berjalan sebagaimana semestinya ataukah tidak. Jika tidak berjalan dengan semestinya, maka dilakukan pengoreksian kegiatan yang sedang berjalan agar dapat tetap mencapai apa yang direncanakan. (Ernie dan Kurniawan, 2005: 317)

Pengawasan operasional Bank dimaksudkan untuk memastikan bahwa kegiatan operasional bank telah berjalan efektif dan efisien serta melakukan perbaikan atas segala permasalahan yang ditemukan. Saran yang dilakukan bank untuk mengawasi efektifitas kegiatan operasionalnya adalah dengan melakukan audit internal.

Audit Internal adalah penelaahan atas prosedur dan metode operasi entitas untuk menentukan tingkat efesiensi dan efektivitasnya. Audit operasional kadang-kadang disebut juga sebagai audit kinerja, audit manajemen atau audit komprehensif. Secara internasional, istilah yang paling sering digunakan untuk audit operasional adalah audit nilai uang (value for money auditing). (Guy, 2004: 419)

Selain itu salah satu permasalahan penting yang harus diawasi manajer adalah bagaimana meningkatkan produktivitas kerja karyawannya sehingga dapat mendukung keberhasilan tujuan yang ingin dicapai. Permasalahan peningkatan produktivitas kerja erat kaitannya dengan permasalahan bagaimana pengawasan dilakukan oleh seorang manajer sehingga dapat mendukung pencapaian tujuan lembaga keuangan.

Sistem Pengendalian Intern (SPI) yang efektif merupakan komponen penting dalam manajemen bank. SPI yang efektif dapat membantu pihak bank dalam menjaga asset bank, menjamin tersedianya pelaporan keuangan dan manajerial yang dapat dipercaya, meningkatkan kepatuhan bank terhadap ketentuan dan peraturan perundang-undangan yang berlaku.

\section{Auditing}

Pengertian auditing adalah suatu proses sistematik untuk memperoleh dan mengevaluasi bukti secara objektif mengenai pernyataan-pernyataan tentang kegiatan dan kejadian ekonomi, dengan tujuan untuk menetapkan tingkat kesesuaian antara pernyataanpernyataan tersebut dengan kriteria yang telah ditetapkan, serta penyampaian hasil-hasilnya kepada pemakai yang berkepentingan. Untuk mengetahui dengan jelas pengertian auditing, berikut ini akan dikemukakan definisi-definisi auditing yang diambil dari beberapa sumber. (Mulyadi, 2014: 7)

Auditing adalah suatu proses pengumpulan dan pengevaluasian bahan bukti tentang informasi yang 
dapat diukur mengenai suatu entitas ekonomi yang dilakukan seseorang yang independen dan kompeten untuk dapat menentukan dan melaporkan kesesuaian informasi dimaksud dengan kriteria-kriteria yang ditetapkan. (Elfadhli, 2015: 2)

Sukrisno Agoes (2014) juga mengungkapkan bahwa Auditing adalah suatu pemeriksaan yang dilakukan secara kritis dan sistematis oleh pihak independen, terhadap laporan keuangan yang telah disusun oleh manajemen beserta catatan-catatan pembukuan dan bukti-bukti pendukungnya, dengan tujuan agar data memberikan pendapat mengenai kewajaran laporan keuangan tersebut.

Menurut Pernyataan Standar Akuntansi Keuangan (PSAK) 2019 pengertian audit adalah Suatu proses sistematis yang bertujuan untuk mengevaluasi bukti yang dikumpulkan atas pernyataan atau asersi mengenai berbagai aksi ekonomi, kejadiankejadian dan melihat tingkat hubungan antara pernyataan atau asersi dengan kenyataan, serta mengkomunikasikan hasilnya kepada pihak-pihak yang berkepentingan.

Secara umum Auditing adalah proses sistematis yang dilakukan oleh seseorang yang kompeten dan independen agar dapat menghimpun dan mengevaluasi bukti-bukti mengenai informasi yang terukur dari asersiasersi tentang berbagai tindakan dan kejadian ekonomi sesuai entitas usaha untuk mempertimbangkan tindakan kesesian (degree of correspindence) dengan kriteria yang ditentukan dan melaporkan hasilnya kepada para pemakai yang berkepentingan. (Perwita, Hastuti dan Ratnawati, 2019: 8)

\section{Audit Internal}

Menurut Lawrence (2009) Arti internal audit adalah proses penilaian yang dilaksanakan secara berurutan dan bersifat obyektif yang dilaksanakan oleh auditor internal kepada aktivitas operasional dan kontrol yang berbeda di dalam organisasi. Audit internal dilaksanakan untuk menetapkan apakah:

1. Informasi mengenai financial dan operasional perusahaan sudah tepat dan dapat dipercaya.

2. Kemungkinan hambatan yang akan dihadapi perusahaan telah diketahiu dan diminimalisir.

3. Peraturan ekternal perusahaan dan kebijakan di internal dapar diterima dan dipatuhi.

4. Aktivitas operasional telah memuaskan.

5. Penggunaan sumber daya perusahaan dipakai secara efektif dan efisien.

Sistem pengendalian intern yang dilakukan membantu menajemen dalam mengkoordinasikan dan mengawasi semua sumber daya perusahaan untuk mencapai tujuan yang telah ditetapkan. Merupakan tanggung jawab direktur dan manajemen untuk membuat dan memelihara sistem pengendalian intern di dalam perusahaan. Namun pihak lain yang 
terkait seperti auditor internal dapat memberikan pertimbangan bagi manajemen dan direktur dalam merumuskan model pengendalian intern yang sesuai untuk dijalankan perusahaan. (Elfadhli, 2015: 31)

Audit internal dapat didefinisikan sebagai suatu fungsi penilaian yang independen dalam suatu organisasi untuk menguji dan mengevaluasi kegiatan organisasi yang dilaksanakan. Tujuan audit internal adalah membantu para anggota organisasi agar dapat melaksanakan tanggung jawabnya secara efektif. Untuk itu, audit internal akan melakukan analisis, penilaian, dan mengajukan saran-saran kepada manajemen organisasi dalam pengambilan keputusan. (Tugiman, 2014: 11)

\section{Peran dan Tanggung Jawab Audit Internal}

Peran dan tanggung jawab auditor sebagai berikut (Mulyadi, 2002)

1. Bertanggung jawab dalam mendeteksi dan melaporkan kecurangan, kekeliruan dan ketidak beresan yang terjadi. Dalam Standar Akuntansi seksi 316 pendeteksian terhadap kekeliruan dan ketidakberesan dapat berupa kekeliruan pengumpulan dan pengolahan data akuntansi, kesalahan penafsiran prinsip akuntansi tentang jumlah, klasifikasi dan cara penyajian, penyajian laporan keuangan yang menyesatkan serta penyalahgunaanaktiva.

2. Tanggung jawab mempertahankan sikap independensi dan konflik. Standar Profesional Akuntan Publik
(SPAP) seksi 2020 harus bersikap jujur, bebas dan kewajiban klien tid meak mempunyai kepentingan dengan klien baik yerhadap manajemen maupun pemilik. Disamping itu sikap mempertahankan indepensi dan penuh integritas serta bebas dari hubungan-hubungan tertentu dalam wujud mempertahankan fakta (independent infect) dan menghindari dari pihak luar merugikan independensinya.

3. Tanggung jawab mengkonfirmasikan informasi yang berguna tentang sifat dan hasil proses audit. SPAP seksi 341 menyatakan bahwa hasil evaluasi yang dilakukan, mengindikasikan adanya ancaman terhadap kelangsungan hidup perusahaan, auditor wajib mengevaluasi rencana manajemen untuk memperbaiki kondisi tersebut. Bila ternyata tidak memuaskan, auditor boleh tidak memberikan pendapat dan perlu diungkapan.

4. Tanggung jawab menemukan tindakan melanggar hukum dari klien.

\section{Efektivitas}

Menurut Ravinto dalam Masruri (2014: 11), Pengertian efektivitas ialah seberapa baik pekerjaan yang dilakukan, sejauh mana orang menghasilkan keluaran sesuai dengan yang diharapkan. Artinya apabila suatu pekerjaan dapat diselesaikan sesuai dengan perencanaan, baik dalam waktu, biaya, maupun mutunya maka dapat dikatakan efektif. 
Efektivitas dapat pula dapat
diketahui dengan cara yakni
menghitung antara output dan tujuan atau dapat juga dikatakan ukuran seberapa jauh tingka toutput tertentu, kebijakan dan prosedur dari organisasi. Efektivitas juga berhubungan dengan derajat keberhasilan suatu operasi pada sektor publik, sehingga suatu kegiatan dikatakan efektif jika kegiatan tersebut mempunyaipengaruh besar terhadap kemampuan menyediakan pelayanan masyarakat yangmempunyai sasaran yang telah ditentukan. (Prabowo dan Pusung, 2015: 421)

Menurut Mardiasmo (2017: 134) Efektivitas adalah ukuran berhasil tidaknya pencapaian tujuan suatu organisasi mencapai tujuannya. Apabila suatu organisasi mencapai tujuan maka organisasi tersebuttelah berjalan dengan efektif. Indikator efektivitas menggambarkan jangkauan akibat dan dampak (outcome) dari keluaran (Output) program dalam mencapai tujuan program. Semakin besar kontribusi output yang dihasilkan terhadap pencapaian tujuan atau sasaran yang ditentukan, maka semakin efektif proses kerja suatu unit organisasi.

Efektifitas $=$ (output Aktual $/$ Output Target) $\geq 1$

Artinya:

1. Apabila hasil perbandingan output aktual dengan output target $<1$ maka efektifitas itu tidak tercapai.

2. Apabila hasil perbandingan output aktual dengan output target $\geq 1$ maka efektifitas itu tercapai.

\section{METODE PENELITIAN}

Jenis penelitian ini merupakan penelitian mix methods, yaitu metode penelitian dengan mengkombinasikan antara dua metode penelitian sekaligus, kualitatif dan kuantitatif dalam suatu kegiataan penelitian, sehingga akan diperoleh data yang akan lebih komprehensif, valid, reliabel, dan obyektif (Sugiyono, 2011: 18).

Penelitian ini menggunakan strategi metode campuran bertahap (sequential mixed methods) Jadi, tahap pertama penyebaran angket atau kuesioner atau instrumen penelitian dan menganalisis data kuantitatif, selanjutnya melakukan wawancara untuk menganalisis data kualitatif dengan tujuan untuk mengetahui peran audit internal dalam meningkatkan efektivitas kegiatan pembiayaan yang dilakukan oleh PT. BPRS Haji Miskin Pandai Sikek. Teknik pengumpulan data yang digunakan adalah observasi, wawancara, kuesioner dan dokumentasi dengan jumlah sampel 39 orang. Alat dalam pengolahan dan analisis yang digunakan adalah uji validitas dan reliabilitas, uji normalias, analisis tegresi linear berganda, uji hipotesis, dan koefisien determinasi $\mathrm{R}^{2}$.

\section{HASIL PENELTIAN DAN PEMBAHASAN}

\section{Uji Validitas}

Pengujian validitas dilakukan untuk mengetahui suatu intrumen alat ukur digunakan dalam penelitian telah menjalankan fungsi ukurnya. Uji 
validitas dalam penelitian ini menggunakan program SPSS 20. Penyebaran kuesioner dilakukan pada 39 orang responden dengan jumlah pernyataan sebanyak 15 item untuk variable bebas (Peranan Audit Internal) dan 15 item untuk variable terikat (Efektivitas Kegiatan Pembiayaan), dimana seluruh item pertanyaan dikategorikan valid dengan syarat $r$ hitung atau nilai pada kolom Corrected Item-Total Correlation lebih besar dar pada $r$ tabel product moment. Dalam hal ini $r$ tabel dicari pada signifikansi 0,05 dengan uji 2 sisi dan jumlah data $(n)=39$, maka didapat $r$ tabel sebesar 0,264

\section{Uji Realiabilitas}

Satu konstruk atau variabel dikatakan reliable jika memberikan nilai Cronbach Alpha $>0.60$. Uji reliabilitas dalam penelitian ini menggunakan program SPSS 20. Hasil pengolahan data yang disajikan dalam tabel menunjukkan bahwa nilai Cronbach Alpha $(\alpha)$ item untuk setiap variabel adalah lebih besar dari 0,60 sehingga item untuk setiap variabel adalah reliabel.

Berikut hasil dari uji reliabilitas variable bebas (Peranan Audit Internal) dan variable terikat (Efektifitas Kegiatan Pembiayaan):

1) Peranan Audit internal

Tabel 3

Uji Realibilitas Audit Internal

\begin{tabular}{|r|c|}
\hline \multicolumn{2}{|c|}{ Reliability Statistics } \\
\hline Cronbach's Alpha & N of Items \\
\hline 0,750 & \\
\hline
\end{tabular}

Sumber: Hasil Output SPSS V.20

Berdasarkan dari tabel di atas, dapat terlihat bahwa nilai Cronbach's Alpha perana audit internal sebesar 0,750 . Hal ini verarti bahwa nilai ini telah melewati syarat relibilitas sebesar 0,6, maka dapat dikatakan bahwa peranan audit internal teruji reliabilitasnya.

2) Efektivitas Kegiatan Pembiayaan

Tabel 4

Uji Realibilitas Efektivitas Kegiataan Pembiayaan

\begin{tabular}{|c|c|}
\hline \multicolumn{2}{|c|}{ Reliability Statistics } \\
\hline Cronbach's Alpha & N of Items \\
\hline 0,668 & 15 \\
\hline
\end{tabular}

Sumber: Hasil Output SPSS V.20 
Berdasarkan dari tabel di atas, dapat terlihat bahwa nilai Cronbach's Alpha perana audit internal sebesar 0,668 . Hal ini verarti bahwa nilai ini telah melewati syarat relibilitas sebesar 0,6, maka dapat dikatakan bahwa peranan audit internal teruji reliabilitasnya.

\section{Uji Normalitas}

Uji normalitas adalah pengujian tentang kenormalan distribusi data. Digunakan untuk mengetahui apakah distribusi data variabel independen dan data variabel dependen adalah nominal. Model regresi yang baik adalah mempunyai distribusi data normal atau mendekati normal. Normal atau tidaknya distribusi sebuah data dapat dilihat dengan menggunakan uji One sample kolmogorov-smirnow, distribusi data dikatakan normal jika nilai sighnifikansi> 0,05 (priyanto, 2012: 256)

Tabel 5

Hasil Uji Normalitas

\begin{tabular}{|c|c|c|}
\hline \multicolumn{3}{|c|}{ One-Sample Kolmogorov-Smirnov Test } \\
\hline & & Unstandardized Residual \\
\hline \multicolumn{2}{|l|}{$\mathrm{N}$} & $\begin{array}{r}2 \\
\end{array}$ \\
\hline \multirow[t]{2}{*}{ Normal Parameters ${ }^{a, b}$} & Mean & 0,1667418 \\
\hline & Std. Deviation & 2,01319656 \\
\hline \multirow[t]{3}{*}{ Most Extreme Differences } & Absolute & 0,078 \\
\hline & Positive & 0,059 \\
\hline & Negative & $-0,078$ \\
\hline \multicolumn{2}{|l|}{ Test Statistic } & 0,078 \\
\hline \multicolumn{2}{|l|}{ Asymp. Sig. (2-tailed) } & $0,200^{c, d}$ \\
\hline \multicolumn{3}{|c|}{ a. Test distribution is Normal. } \\
\hline \multicolumn{3}{|c|}{ b. Calculated from data. } \\
\hline \multicolumn{3}{|c|}{ c. Lilliefors Significance Correction. } \\
\hline \multicolumn{3}{|c|}{ d. This is a lower bound of the true significance. } \\
\hline
\end{tabular}

Sumber : Hasil Output SPSS V.20

Dari hasil uji normalitas diatas diketahui nilai Asynp. Sig. Sebesar 0,200 yang mana lebih besar dari tingkat signifikansi $(0,05)$. Artinya data sudah terdistribusi secara normal.

\section{Uji Regresi Linear Sederhana}

Analisis ini bertujuan untuk mengetahui seberapa besar pengaruh variabel indenpenden terhadap variabel dependen. Regresi digunakan untuk mengukur besar pengaruh variabel bebas terhadap variabel terikat dan memprediksi variabel terikat dengan menggunakan variabel bebas (Sugiyono: 188). Berikut hasil perhitungan regresi linear sederhana dengan menggunakan program SPSS 20. 
Tabel 6

Hasil Uji Regresi Linear Sederhana

\begin{tabular}{|l|r|r|rr|}
\hline \multicolumn{4}{|c|}{ Coefficients $^{\mathbf{a}}$} \\
\hline \multirow{2}{*}{ Model } & Unstandardized Coefficients & Standardized Coefficients \\
\cline { 2 - 5 } & \multicolumn{1}{|c|}{ B } & Std. Error & Beta & 0,267 \\
\hline (Constant) & 51,051 & 10,068 & & \\
\hline X & 0,234 & 0,154 & & \\
\hline \multicolumn{2}{|l}{ a. Dependent Variable: $Y$}
\end{tabular}

Sumber: Hasil Output SPSS V.20

Berdasarkan data hasil uji regresi linear sederhana pada tabel yang disajikan, maka diperoleh persamaan regresi sebagai berikut:

$$
\begin{aligned}
& Y=a+b X \\
& Y=51,051+0,234 X
\end{aligned}
$$

Adapun hasil dari persamaan regresi diatas dapat diuraikan sebagai berikut:

a. Nilai konstanta $=51,051$ merupakan nilai konstanta yang diartikan bahwa jika variabel peranan audit internal penggunaan konstan maka nilai Efektivitas kegiatan pembiayaan sebesar 51,051

b. Koefisien regresi $\mathrm{X}=0,234$ menunjukan bahwa variabel peranan audit internal berpengaruh positif terhadap efektivitas kegiatan pembiayaan yaitu meningkat sebesar 0,234

\section{Uji Signifikan Parsial (Uji-t)}

Uji $t$ bertujuan menunjukan seberapa jauh pengaruh satu variabel penjelasan/independen secara individual dalam menerangkan variasi variabel dependen. Apabila nilai hitung $>$ Ttabel dan nilai signifikan lebig kecil dari 0,05 maka dapat disimpulkan bahwa variabel bebas berpengaruh signifikan terhadap variabel terikat (Ghozali,2011:98). Berikut hasil Uji t dengan menggunakan program SPSS 20.

Tabel 7

\begin{tabular}{|c|c|c|c|c|c|c|}
\hline \multicolumn{7}{|c|}{ Coefficients ${ }^{a}$} \\
\hline & & \multicolumn{2}{|c|}{$\begin{array}{l}\text { Unstandardized } \\
\text { Coefficients }\end{array}$} & $\begin{array}{l}\text { Standardized } \\
\text { Coefficients }\end{array}$ & \multirow[b]{2}{*}{$\mathrm{T}$} & \multirow[b]{2}{*}{ Sig. } \\
\hline \multicolumn{2}{|c|}{ Model } & $\mathrm{B}$ & \begin{tabular}{l|l} 
Std. Error \\
\end{tabular} & Beta & & \\
\hline \multirow[t]{2}{*}{1} & (Constant) & 51,051 & 10,068 & & 5,070 &, 000 \\
\hline & $\mathrm{X}$ & 0,234 & 0,154 & 0,267 & 1,720 & 0,041 \\
\hline
\end{tabular}

Hasil Uji Signifikan Parsial (Uji-t)

Sumber: Hasil Output SPSS V.20 
Dari hasil uji hipotesis diatas diketahui $\mathrm{T}$ hitung $=1,720$ dan signifikansi sebesar 0,041 yang artinya $\mathrm{T}$ hitung lebih besar dari $\mathrm{T}$ Tabel $(1,720$ $>1,685)$ dan niali signifikansi lebih kecil dari 0,05 $(0,041<0,05)$. Jadi kesimpulannya $\mathrm{HO}$ ditolak dan $\mathrm{Ha}$ diterima. Artinya variabel Peranan audit internal berpengaruh signifikan terhadap Efektivitas Kegiatan pembiayaan.

\section{Uji Koefisien Determinasi $\left(\mathrm{R}^{2}\right)$}

Analisis ini digunakan untuk mengetahui persentase sumbangan pengaruh variabel independen terhadap variabel dependen. Melalui Koefisien Determinasi( $\left.\mathrm{R}^{2}\right)$ dapat diketahui sejauh mana variabel Peranan Audit internal mampu menjelaskan variabel Efektivitas Kegiataan pembiayaan.

Tabel 8

Hasil Uji Koefisein Determinasi

\begin{tabular}{|l|c|c|c|cr|}
\hline \multicolumn{7}{|c|}{ Model Summary } \\
\hline Model & $\mathrm{R}$ & R Square & $\begin{array}{c}\text { Adjusted R } \\
\text { Square }\end{array}$ & $\begin{array}{c}\text { Std. Error of the } \\
\text { Estimate }\end{array}$ \\
\hline 1 & $0,267 \mathrm{a}$ & 0,071 & 0,041 & & 2,046 \\
\hline \multicolumn{2}{|l}{ a. Predictors: (Constant), X }
\end{tabular}

Sumber: Hasil Output SPSS V.20

Dari hasil uji Koefisien Determinasi di atas diketahui nilai Adjust R2 $=0,041$. Artinya variabel Peranan audit internal mempengaruhi variabel Efektivitas kegiatan pembiayaan sebesar 4,1\%. Sisanya 95,9 dipengaruhi oleh variabel lain yang tidak dimaksukan dalam penelitian ini.

Berdasarkan analisis statistik regresi antara peranan audit internal dengan efektivitas kegiataan pembiayaan di peroleh koefisien determinasi $(\mathrm{R} 2)=0,041$. Hal ini menunjukan bahwa peranan audit internal berpengaruh signifikan terhadap efektifitas kegiatan pembiayaan pada PT.BPRS Haji Miskin Pandai Sikek. Jika audit internal melaksanakan tugasnya dengan baik, maka tugas atau kinerja operasional perusahaan akan berjalan dengan baik dan penuh tanggung jawab.

Peranan audit internal pada PT.BPRS Haji Miskin Pandai Sikek dalam meningkatkan efektifitas kegiatan pembiayaan memiliki peranan yang cukup baik. Hal ini didukung juga dengan pelaksaanan pemberian pembiayaan dan pelaksanaan audit yang dilakukan pad PT.BPRS Haji Miskin tersebut. Selain itu PT.BPRS Haji Miskin Pandai Sikek selalu berupaya mentaati setiap peraturan dan hukum pembiayaan yang berlaku baik peraturan dan kebijakan yang berasal dari internal perusahaan maupun peraturan dan kebijakan yang berasal dari pusat atau pemerintah. PT.BPRS Haji Miskin Pandai Sikek telah mentaati peraturan yang digariskan oleh pemerintah 
mengenai pembentukan audit internal Bank. Berdasarkan hal tersebut maka dapat disimpulkan bahwa ketaatan perusahaan terhadap hukum dan peraturan yang berlaku telah memadai hal ini terlihat dari ketaatan PT.BPRS Haji Miskin Pandai Sikek dalam menjalankan prosedur pembiayaan yang telah ditetapkan. Efektivitas kegiatan perpembiayaanan akan tercapai jika NPF yang dicapai dibawah standar BI, yaitu 5\%. Berikut adalah kolektabilitas modal kerja PT.BPRS Haji Miskin Pandai Sikek.

Tabel 9

Kualitas Pembiayaan PT.BPRS Haji Miskin Pandai Sikek

Per 31 Desember 2017, 2018, dan 2019

\begin{tabular}{|l|r|r|r|}
\hline \multicolumn{1}{|c|}{$\begin{array}{c}\text { Kualitas } \\
\text { Pembiayaan }\end{array}$} & \multicolumn{1}{c|}{2017} & \multicolumn{1}{c|}{2018} & \multicolumn{1}{c|}{2019} \\
\hline Lancar & 27.549 .907 .842 & 33.838 .458 .090 & 33.838 .458 .090 \\
\hline Kurang lancar & 287.143 .054 & 258.706 .531 & 258.706 .531 \\
\hline Diragukan & 466.862 .438 & 254.063 .733 & 254.063 .733 \\
\hline Macet & 634.300 .685 & 1.096 .296 .063 & 1.096 .296 .063 \\
\hline $\begin{array}{l}\text { Jumlah } \\
\text { Pembiayaan } \\
\text { Disalurkan }\end{array}$ & 28.938 .214 .019 & 35.447 .524 .417 & 35.447 .524 .417 \\
\hline
\end{tabular}

Sumber: PT.BPRS Haji Miskin Pandai Sikek

Tabel 10

Non Peformance Financing PT.BPRS Haji Miskin Pandai Sikek

Per 31 Desember 2017, 2018, dan 2019

\begin{tabular}{|c|c|c|c|}
\hline \multirow{2}{*}{ Tahun } & $\mathbf{1}$ & $\mathbf{2}$ & $\begin{array}{c}\text { [ 2:1 } \\
\text { ]x100\% }\end{array}$ \\
\cline { 2 - 4 } & $\begin{array}{c}\text { Jumlah } \\
\text { Pembiayaan }\end{array}$ & Jumlah NPF & $\begin{array}{c}\text { Persentase } \\
\text { NPF }\end{array}$ \\
\hline 2017 & 28.938 .214 .019 & 1.388 .306 .177 & $4.7 \%$ \\
\hline 2018 & 34.862 .979 .441 & 1.609 .066 .327 & $4.6 \%$ \\
\hline 2019 & $42.525 .969,236$ & 1.609 .066 .327 & $3.7 \%$ \\
\hline
\end{tabular}

Sumber: Hasil Olahan

Berdasarkan perhitungan terhadap tingkat kolektabilitas pembiayaan yang di salurkan PT.BPRS Haji Miskin Pandai Sikek tahun 2017, rasio NPF sebesar 4.7\%, pada tahun 2018 menurun menjadi $4.6 \%$ dan pada tahun 2019 PT. BPRS Haji Miskin Berhasil menurunkan tingkat NPF menjadi 3.7\%. itu berarti PT. BPRS Haji Miskin Berhasil meningkatkan Efektifitas Pembiayaan yang di salurkannya.

Terjaganya tingkat rasio Non Peformance Financing (NPF) di bawah $5 \%$ cenderung berpengaruh terhadap 
naiknya pertumbuhan pembiayaan pada PT. BPRS Haji Miskin pandai sikek dan dengan terjagaya rasio Non Peformance Financing (NPF) di bawah 5\% maka Bank tidak akan ragu dalam memberikan pembiayaan kepada masyarakat atau nasabah, ini bisa terlihat dari jumlah pembiayaan yang disalurkan PT. BPRS Haji Miskin Pandai Sikek dari tahun ke tahun makin meningkat.

Peranan audit internal dalam penelitian ini terbukti memiliki peranan dalam meningkatkan efektivitas kegiatan pembiyaan pada PT. BPRS Haji Miskin. Berdasarkan hasil wawancara auditor internal memiliki peranan terhadap efektifitas pembiayaan dengan cara mendeteksi dan melaporkan kecurangan, melakukan verifikasi data atau dokumen debitur, dan juga menilai kelayakan pemberian pembiayaan terhadap debitur. Berdasarkan tingkat persentase nilai NPF pada tahun 2017 sebesar 4,7\% menjadi sebesar 3,7\% pada tahun 2019 juga membuktikan bahwa audit internal berperan dalam meningkatkan efektifitas kegiataan pembiayan.

\section{PENUTUP}

Berdasarkan hasil pembahasan mengenai Peranan Audir Internal dalam Meningkatkan efektifitas Kegiatan Pembiayaan pada PT.BPRS Haji Miskin Pandai sikek. Maka dapat disajikan beberapa kesimpulan dari hasil analisis sebagai berikut:

1. Peranan Audit Internal positif terhadap Efektivitas Kegiataan pada
PT.BPRS Haji Miskin Pandai Sikek. Sedangkan pada Uji Signifikansi Parsial (Uji-t) mengungkapkan bahwa Peranan Audit internal berpengaruh signifikan terhadap Efektivitas kegiatan pembiayaan, hal ini dapat diketahui dari nilai probabilitas signifikansi sebesar 0,001 yang berada dibawah $5 \%$ atau 0,05 . Untuk menentukan besar variabel independen dapat menjelaskan variabel dependen diperoleh hasil $R$ Square atau nilai koefisien determinasi $\left(\mathrm{R}^{2}\right)$ dari penelitian ini adalah sebesar 0,041 atau 4,1\%. Hal ini menjelaskan bahwa variabel Audit Internal mampu menjelaskan variabel Efektivitas kegiataan pembiayaan sebesar 4,1\% Sisanya 95,9 dipengaruhi oleh variabel lain yang tidak dimaksukan dalam penelitian ini.

2. Pelaksanaan pemberian pembiayaan pada PT. BPRS Haji Miskin Pandai Sikek sudah efektif, hal ini di dukung oleh:

a. Pemberian pembiayaan yang dilakukan secara konsisten didasarkan pada prinsip 5C (Character, Capacity, Capital, Collateral and Condition of economy)

b. Pembiayaan yang diberikan sudah tercover atau di tutup dengan agunan yang telah memadai.

3. Pelaksanaan Audit Internal pada PT.BPRS Haji Miskin telah baik hal karena pelaksanaannya telah sesuai 
dengan Pedoman Standar Sistem Pengendalian Intern bagi Bank Umum yang dikeluarkan oleh Bank Indonesia dan kriteria subkomponen penilaian sesuai ketentuan yang telah ditetapkan oleh The Committee of Sponsoring Organization (COSO).

\section{Saran}

Adapun saran yang dapat peneliti sampaikan dari hasi penelitian ini adalah:

1. Penulis menyaranan kepada Auditor Internal agar selalu meningkatkan peranan Audir internal dalam meningkatkan efektivitas Kegiataan pembiayan.

2. Penulis menyarankan kepada karyawan atau staff di bidang pembiayaan agar selalu mempergatikan prinsip 5C dalam pemberian pembiayaan kepada calon nasabah. Agar pembiayaan tidak meningkat persentas nilai NPF atau pembiayaan yang bermasalah.

\section{DAFTAR KEPUSTAKAAN}

Agoes, Sukrisno. 2014. Auditing petunjuk praktis pemeriksaan akuntan oleh akuntan publik. Jakarta: Salemba Empat.

Ernie T. S \& Kurniawan, Pengantar manajemen. Jakarta, Kencana Pranada Media Group

Guy M Dan, 2003. Auditing, Jilid II, Erlangga, Jakarta.

Sugiyono, Kualitatif (Teori, praktek dan Riset penelitian kualitatif. Bandung: Alfabeta, 2010.
Sugiyono, Metode Pendidikan Pendekatan Kuantitatif, kualitatif, dan R\&D. Bandung: Alfabeta, 2013, edisi I

Sugiyono, Metode Pendidikan Pendekatan Kuantitatif, kualitatif, dan R\&D. Bandung: Alfabeta, 2014, edisi II

Sugiyono, Metode Penelitian Kualitatif: Beberapa konsep dasar untuk penelitian skripsi dan analisis data dengan menggunakan spss, Yogyakarta: Budi utama: 2019

Peraturan Bank Indonesia Nomor: 1/6/PBI/1999 Penugasan Direktur Kepatuhan dan Penugasan Direktur Kepatuhan dan Penerapan Standar pelaksanaan Fungsi Audit Intern Bank Umum

Undang-Undang Republik Indonesia Nomor 21 Tahun 2008 tentang Perbankan Syariah (Bandung: Citra Umbara, 2013)

Masruri. 2014. Analisis Efektifitas Program Nasional Pemberdayaan Masyarakat MadaniPerkotaan (PNPM-MP) (Studi Kasus Pada Kecamatan Banyu Kabupaten Bulungan Tahun 2010). Goverance and Public Policy

Mulyadi, Auditing.Jakarta: Salemba Empat, 2014

Mulyadi. Auditing Buku 1, Edisi Keenam. Jakarta: Salemba Empat. 2002

Lawrence B Sawyer, JD, CIA, PA, Mortimer A. Dittenhofer, Ph.D.,CIA, James H. Scheiner, Ph. D. 2009. Audit Internal Sawyer. Jakarta: Salemba Empat.

Tugiman, Hiro. 2014. Standar Profesi Audit Internal. Yogyakarta: Kanisiu 